\title{
Effects of C-reactive protein on human pulmonary vascular cells in chronic thromboembolic pulmonary hypertension
}

\author{
Marijke Wynants*, , Rozenn Quarck*,\$, Alicja Ronisz*, Ernesto Alfaro-Moreno\#, \\ Dirk Van Raemdonck", Bart Meyns ${ }^{+}$and Marion Delcroix*
}

ABSTRACT: Chronic thromboembolic pulmonary hypertension (CTEPH) is characterised by proximal pulmonary vascular obstruction by thrombo-fibrotic material, the origin of which has not been elucidated. Enhanced inflammation could contribute to persistent obstruction by impairing pulmonary vascular cell function in CTEPH. We investigated C-reactive protein (CRP) effects on pulmonary vascular cell function in vitro.

Primary cultures of proximal pulmonary endothelial cells (ECs) and smooth muscle cells (SMCs) from CTEPH and nonthromboembolic pulmonary hypertension (PH) patients were established. Recombinant CRP effects on mitogenic activity, adhesion capacity, endothelin-1 and von Willebrand factor (vWF) secretion and intercellular adhesion molecule (ICAM)-1 and vascular cell adhesion molecule-1 expression were investigated in ECs and/or SMCs. Expression of the CRP receptor, lectin-like oxidised low-density lipoprotein receptor (LOX)-1, was evaluated in proximal pulmonary arterial tissue and cells by Western blotting and immunofluorescence.

CRP increased CTEPH-SMC proliferation by $250 \%$. CRP increased adhesion capacity, endothelin-1 and vWF secretion by CTEPH-ECs by 37\%, 129\% and 694\%, respectively. CRP-induced adhesion of CTEPH-ECs to monocytes was mediated by ICAM-1. CRP had no effect on cells from nonthromboembolic PH patients, probably because of overexpression of LOX-1 in CTEPH. Local expression of CRP was detected in ECs and SMCs within pulmonary arterial tissue.

CRP may contribute to persistent obstruction of proximal pulmonary arteries in CTEPH by promoting vascular remodelling, endothelial dysfunction and in situ thrombosis.

KEYWORDS: C-reactive protein, chronic thromboembolic pulmonary hypertension, endothelial cells, inflammation, smooth muscle cells

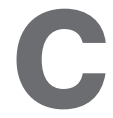
hronic thromboembolic pulmonary hypertension (CTEPH) is one of the main causes of severe pulmonary hypertension. CTEPH is characterised by intraluminal thrombus organisation and fibrous stenosis or complete obliteration of proximal pulmonary arteries. The consequence is an increased pulmonary vascular resistance resulting in pulmonary hypertension $(\mathrm{PH})$ and progressive right heart failure. Pulmonary embolism, either as single or recurrent episodes, is thought to be the initiating event followed by progressive pulmonary vascular remodelling. CTEPH mainly differs from pulmonary arterial hypertension (PAH) by the proximal location of pulmonary artery obliteration [1].
To date, the physiopathology of CTEPH remains poorly understood. Proximal lesions share similarities with atherosclerotic plaques, including media thickening and neointima formation [2]. Besides evidence of dysregulated thrombosis and/or thrombolysis, an elevated prevalence of inflammatory diseases has been observed in CTEPH patients [3]. Accordingly, plasma levels of tumour necrosis factor- $\alpha$ are elevated in CTEPH [4] and elevated pulmonary vascular resistance is correlated with increased expression of the CCL2 chemokine monocyte chemoattractant protein- 1 in the plasma and large pulmonary arteries of CTEPH patients [5]. Furthermore, staphylococcal infection has been shown to prevent the resolution of inferior vena
AFFILIATIONS

*Respiratory Disease Dept, Katholieke Universiteit, "Thoracic Surgery, Universitaire Ziekenhuizen Leuven,

${ }^{+}$Cardiac Surgery Dept, Universitaire Ziekenhuizen Leuven, Leuven, Belgium.

\#Instituto Nacional de Cancerologia, Mexico City, Mexico.

${ }^{\S}$ These authors contributed equally to the study.

CORRESPONDENCE

M. Delcroix

Dept of Pneumology

Universitaire Ziekenhuizen Leuven

Herestraat 49

B-3000 Leuven

Belgium

E-mail: marion.delcroix@

uzleuven.be

Received:

Nov 132011

Accepted after revision:

Jan 092012

First published online:

Jan 202012 
cava thrombi in rodents and is observed in most patients with ventriculo-atrial shunt or pacemaker-related CTEPH [6].

We have recently shown that CTEPH patients display elevated circulating C-reactive protein (CRP) levels [7]. CRP, a marker of acute inflammation and tissue damage, is an independent risk factor for cardiovascular and systemic diseases [8]. Besides its commonly accepted role of bystander in various inflammatory diseases, CRP also plays an active role in atherogenesis [9, 10]. Indeed CRP locally induces the production of vasoconstrictive, thrombotic, proliferative and inflammatory molecules in systemic arteries [10]. These molecules could also be involved in the pathogenesis of CTEPH.

Endothelin (ET)-1 and von Willebrand factor (vWF) are important players in the pathophysiology of pulmonary hypertension [11]. ET-1 and vWF plasma levels are elevated in patients with CTEPH and correlate with clinical parameters [12-14]. ET-1 is secreted by CRP-stimulated venous endothelial cells [15]. vWF is released from its endothelial storage compartment, the Weibel-Palade bodies, when the endothelium is damaged and is consequently considered as a marker of endothelial dysfunction [16]. vWF stabilises factor VIII, a key player of the coagulation cascade and a risk factor for CTEPH, and therefore contributes to thrombogenesis [17].

The mechanisms resulting in the persistence of obstructing fibro-thrombotic material in CTEPH require being unravelled. We consequently hypothesised that enhanced inflammation may be involved in that process. Our objective was to investigate whether CRP could be more than a bystander in CTEPH, by investigating its effect on vascular remodelling, endothelial dysfunction and thrombosis in proximal pulmonary vessels of CTEPH patients, using primary cultured pulmonary artery smooth muscle cells (SMCs) and endothelial cells (ECs), and pulmonary arterial tissue.

\section{MATERIALS AND METHODS}

\section{Study population}

Proximal pulmonary vascular tissue was obtained from 1) CTEPH patients who underwent a pulmonary endarterectomy (PEA) and 2) patients with other causes of $\mathrm{PH}$ (PAH or due to lung diseases), assigned as nonthromboembolic $\mathrm{PH}$, who underwent a lung transplantation. Demographics were recorded. Pulmonary haemodynamic parameters were collected in anaesthetised patients in the operation room before starting lung transplantation or PEA. Plasma CRP levels were measured in the University Hospital routine laboratory as previously described [7] within $24 \mathrm{~h}$ before PEA and lung transplantation. The study protocol was approved by the Institutional Ethics Committee of the University Hospital of Leuven (Leuven, Belgium) and participants gave written informed consent.

\section{Tissue collection}

At the time of lung transplantation or PEA, a 2-cm piece of proximal pulmonary artery, free from thrombotic material, was stored in cell culture media containing antibiotics and antimycotics at $4{ }^{\circ} \mathrm{C}$. Two pieces were quickly frozen in liquid nitrogen and stored at $-80^{\circ} \mathrm{C}$ until protein extraction. Another piece was fixed in $4 \%$ paraformaldehyde and cryoembedded.

\section{Cell culture}

Proximal ECs were obtained by collagenase type II $\left(1 \mathrm{mg} \cdot \mathrm{mL}^{-1}\right.$; Life Technologies, Ghent, Belgium) digestion in Hank's balanced salt solution for $20 \mathrm{~min}$ at $37^{\circ} \mathrm{C}$. ECs were seeded on gelatinecoated (Sigma-Aldrich, Bornem, Belgium) cell culture flasks. Immunomagnetic purification of ECs was performed using antiplatelet endothelial cell adhesion molecule-1, also known as CD31, monoclonal antibody-labelled beads, according to the manufacturer's instructions (Miltenyi Biotec, Utrecht, The Netherlands). EC morphology was confirmed by $>95 \%$ cells being positive for CD31, vWF and DiI-labelled acetylated low density lipoprotein (LDL) staining. Proximal SMCs were isolated using an explant-outgrowth method. SMCs were seeded on fibronectin-coated (R\&D Systems, Abington, UK) cell culture flasks. To determine the phenotypic characteristics of cultured SMCs, cells were assessed for expression of muscle-specific contractile and cytoskeletal proteins including smooth muscle $\alpha$ actin, desmin and smooth muscle myosin heavy chain. ECs and SMCs were used between passages 3 and 6 .

ECs were cultured in M199 medium (Life Technologies), supplemented with $20 \%$ fetal bovine serum (FBS) $100 \mathrm{U} \cdot \mathrm{mL}^{-1}$ penicillin, $100 \mu \mathrm{g} \cdot \mathrm{mL}^{-1}$ streptomycin, $1.25 \mu \mathrm{g} \cdot \mathrm{mL}^{-1}$ fungizone (Life Technologies), $10 \mathrm{U} \cdot \mathrm{mL}^{-1}$ heparin (Aventis, Brussels, Belgium) and $5 \mathrm{ng} \cdot \mathrm{mL}^{-1} \alpha$-fibroblast growth factor (R\&D Systems). SMCs were grown in Dulbecco's modified Eagle's medium (DMEM) (Life Technologies) supplemented with 10\% FBS, penicillin, streptomycin and fungizone. U937 cells were cultured in RPMI (Life Technologies) containing 10\% FBS, penicillin, streptomycin and fungizone.

\section{Cell proliferation}

Subconfluent SMCs and ECs were starved for $24 \mathrm{~h}$ in DMEM and M199 supplemented with $0.2 \%$ FBS, respectively. Mitogenic activity of ECs and SMCs was measured in the presence of increasing concentrations of CRP (endotoxin-free, highly purified human recombinant CRP, R\&D Systems) plus $0.5 \mu \mathrm{Ci} \cdot \mathrm{mL}^{-1}$ of $\left[{ }^{3} \mathrm{H}\right]$-thymidine (74 GBq.mmol ${ }^{-1}$; GE Healthcare, Buckinghamshire, UK) for $48 \mathrm{~h}$. Trichloroacetic acid-insoluble material was solubilised in $0.2 \mathrm{~N} \mathrm{NaOH}$ and radioactivity incorporation was quantified in a $\beta$-scintillation liquid counter (LS5000CE; Beckman, Fullerton, CA, USA).

\section{Cell adhesion assay}

Confluent ECs were starved for $6 \mathrm{~h}$ and stimulated with human recombinant CRP $\left(10 \mathrm{ng} \cdot \mu \mathrm{L}^{-1}\right)$ for $3 \mathrm{~h}$. Conditioned medium was collected and stored at $-20^{\circ} \mathrm{C}$ until further use. Human monocytic U937 cells in suspension were radiolabelled with $1 \mu \mathrm{Ci}\left[{ }^{3} \mathrm{H}\right]$-thymidine per $10^{6}$ cells for $48 \mathrm{~h}$ and added $\left(5 \times 10^{5}\right.$ per well $)$ to the endothelial cell monolayer for $3 \mathrm{~h}$ at $37^{\circ} \mathrm{C}$. Nonadherent cells were washed out. Radioactivity incorporated into monocytes attached to the EC monolayer was quantified as described above.

\section{Adhesion molecule expression at cellular surface}

Cells were incubated with CRP $\left(10 \mathrm{ng} \cdot \mu \mathrm{L}^{-1}\right)$ for $3 \mathrm{~h}$ at $37^{\circ} \mathrm{C}$ and fixed with paraformaldehyde. Adhesion molecule expression was performed by using antibodies against intercellular adhesion molecule (ICAM)-1 or vascular cell adhesion molecule (VCAM)-1 (R\&D Systems). Fluorescence labelling was obtained using the secondary antibodies Alexa594 goat anti-mouse 
(Life Technologies). Staining with 4',6-diamidino-2-phenylindole (DAPI) was used to visualise nuclei.

\section{Immunofluorescence on tissue}

Co-localisation of lectin-like oxidised LDL (oxLDL) receptor (LOX)-1 and CRP with ECs or SMCs was performed on $10-\mu \mathrm{m}$ cryosections using a mixture of two primary antibodies against CD31 (ECs; Dako, Heverlee, Belgium) or $\alpha$-smooth muscle actin (SMA; SMCs, Dako) and LOX-1 (Abcam, Cambridge, UK) or CRP (Abcam). Fluorescence labelling was obtained using the secondary antibodies Alexa488 goat anti-mouse, Alexa594 goat anti-rabbit or Alexa594 goat anti-sheep (Life Technologies). Staining with DAPI was used to visualise nuclei.

\section{Western blotting}

Expression of LOX-1, a potential receptor of CRP, in pulmonary vascular tissue and in cultured endothelial cells was performed by Western blotting using specific primary antibodies against LOX-1 (Abcam). $\beta$-actin was used as an internal control. Horseradish peroxidase-conjugated donkey anti-rabbit immunoglobulin (Ig)G for anti-LOX-1 and anti-mouse IgG (Kackson, Suffolk, UK) for anti- $\beta$-actin were used as secondary antibodies. Peroxidase staining was revealed with a chemiluminescence kit (GE Healthcare, Amersham, UK) and performed with films exposed at room temperature. Protein expression was quantified using the Photoprint imaging system and the BIO-1D software (Vilber Lourmat, Marne-la-Vallée, France).

\section{Endothelin (ET)-1 measurement}

ET-1 levels were measured in the collected conditioned medium of ECs using an ELISA kit following the manufacturer's instructions (R\&D Systems).

\section{vWF measurement}

vWF antigen concentrations were determined in conditioned medium of CRP-stimulated ECs collected after wash-out of 4 , 18, 24 and $48 \mathrm{~h}$ by ELISA with rabbit polyclonal anti-human vWF (Dako) as described elsewhere [18].

\section{Statistical analysis}

Database management and statistical analyses were performed using SAS Enterprise Guide 4.1 (SAS Institute Inc., Cary, NC, USA) and GraphPad Prism 4.01 (GraphPad Software Inc., La Jolla, CA, USA). Data are presented as mean \pm SEM in the figures. Differences between the two groups were analysed using one- or two-way ANOVA test followed by post hoc tests or t-test. A value of $\mathrm{p}<0.05$ was considered statistically significant. All p-values were for two-sided tests.

A detailed method section can be found in the online supplementary material.

\section{RESULTS}

\section{Patient characteristics}

We obtained proximal pulmonary arterial tissue from 26 CTEPH patients and 15 patients with nonthromboembolic $\mathrm{PH}$ (six PAH, and nine $\mathrm{PH}$ due to lung diseases including chronic obstructive pulmonary disease (COPD), idiopathic pulmonary fibrosis and sarcoidosis). Among the PAH patients, three had idiopathic PAH, two PAH associated with congenital heart disease and one PAH associated with anorexigen intake. Except for one patient with a very complex form of congenital cardiopathy, all PAH patients were under parenteral prostanoid therapy, together with bosentan and/or sildenafil, at the moment of the transplantation. Demographics, pulmonary haemodynamics and circulating CRP levels were likely to be similar in both groups (table 1).

\section{Effects of recombinant CRP on pulmonary artery cells in vitro}

Increasing CRP concentrations significantly increased CTEPHSMC mitogenic activity by $250 \%$, but had no effect on $\mathrm{PH}-$ SMCs ( $\mathrm{p}=0.003$; fig. 1a). CRP had no effect on EC mitogenic activity (fig. 1b). CRP increased human monocytic cells (U937) cell adhesion to CTEPH-ECs by $37 \%(p<0.005)$ whereas it had no effect on adhesion capacity of PH-ECs (fig. 2). CRP induced the expression of ICAM-1 exclusively at CTEPH-EC surface (fig. 3), whereas it had no effect on VCAM-1 expression (data not shown). In addition, we did not observe any significant difference regarding response to CRP between cells isolated from $\mathrm{PAH}$ patients and cells isolated from patients with $\mathrm{PH}$ due to lung diseases (data not shown).

\section{CRP receptors expression}

CRP Fc $\gamma$ receptor CD64 mRNA was equally expressed in $\mathrm{PH}$ and CTEPH pulmonary vascular tissue, whereas CD32 mRNA expression was significantly upregulated in CTEPH (data not shown). However, CD32 protein expression was similar in both CTEPH and PH (data not shown). By contrast, LOX-1 protein expression was significantly upregulated in CTEPH pulmonary artery tissue and cultured ECs $(p<0.005$ and $\mathrm{p}<0.05$, figs $4 \mathrm{a}$ and $\mathrm{b}$ ). LOX-1 co-localised with CD31 positive CTEPH-ECs, but not with CD31 positive PH-ECs (figs 4c and d). As CRP only had significant effect on pulmonary cells from CTEPH patients in vitro, probably through an enhanced expression of LOX-1 receptor, further experiments were performed on cells or tissue from CTEPH patients.

\begin{tabular}{|c|c|c|}
\hline & Nonthromboembolic PH & CTEPH \\
\hline Subjects $\mathbf{n}$ & 15 & 26 \\
\hline Age yrs & $50 \pm 10$ & $59 \pm 12$ \\
\hline Sex female \% & 50 & 59 \\
\hline Mean $P$ pa $\mathbf{m m H g}$ & $42 \pm 13$ & $43 \pm 12$ \\
\hline RAP $\mathrm{mmHg}$ & $12 \pm 3$ & $11 \pm 5$ \\
\hline TPR dyne $\cdot \mathbf{s} \cdot \mathrm{cm}^{-5}$ & $727 \pm 321$ & $1082 \pm 576$ \\
\hline $\mathrm{CO} L \cdot \mathrm{min}^{-1}$ & $5.15 \pm 1.62$ & $3.64 \pm 1.35$ \\
\hline CRP $\mathrm{mg} \cdot \mathrm{L}^{-1}$ & $8.4(5.1-14.0)$ & $5.0(2.9-8.5)$ \\
\hline \multicolumn{3}{|c|}{$\begin{array}{l}\text { Data are presented as mean } \pm \text { SEM or geometric mean ( } 95 \% \text { confidence inter- } \\
\text { val), unless otherwise indicated. Circulating CRP and haemodynamic para- } \\
\text { meters were measured at the time of pulmonary endarterectomy or } \\
\text { transplantation. PH: pulmonary hypertension; CTEPH: chronic thromboembolic } \\
\text { pulmonary hypertension; Ppa: pulmonary arterial pressure (measured by right } \\
\text { heart catheterisation); RAP: right atrial pressure; TPR: total pulmonary vascular } \\
\text { resistance; CO: cardiac output; CRP: C-reactive protein. }\end{array}$} \\
\hline
\end{tabular}



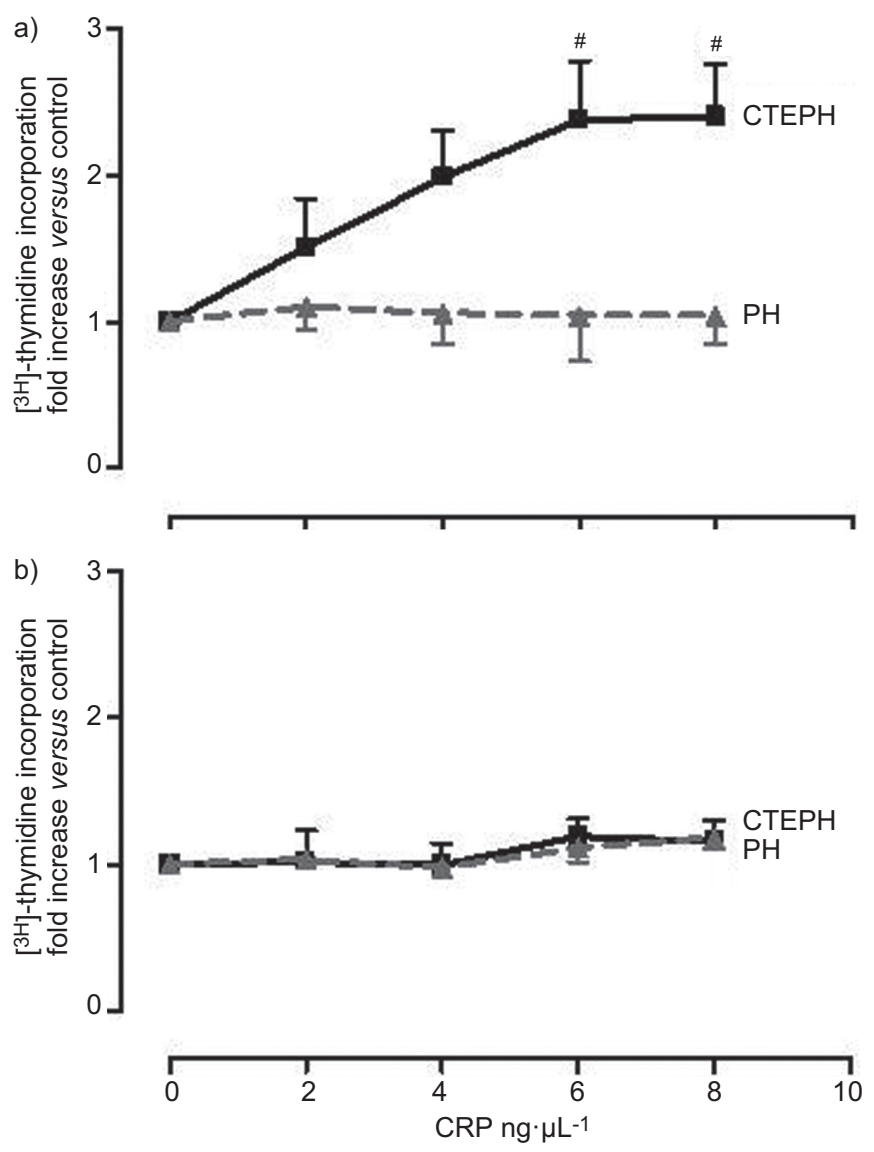

FIGURE 1. Effects of C-reactive protein (CRP) on pulmonary vascular cell proliferation. a) Mitogenic activity of proximal smooth muscle cells isolated from patients with nonthromboembolic pulmonary hypertension $(\mathrm{PH} ; \mathrm{n}=3)$ and chronic thromboembolic pulmonary hypertension (CTEPH) patients $(n=3)$. ANOVA $p=0.003$. \#: $p=0.02$ versus $\mathrm{PH}$. b) Mitogenic activity of proximal endothelial cells isolated from patients with nonthromboembolic $\mathrm{PH}(\mathrm{n}=3)$ and CTEPH patients $(n=3)$. For each patient, one or two independent experiments were performed in triplicate.

\section{Effects of CRP on the secretion of vasoconstrictors and thrombotic factors}

CRP increased significantly the secretion of ET- 1 by $129 \%$ and the secretion of vWF by $694 \%$ by CTEPH-ECs (fig. 5). CRP did not induce any release of factor VIII or tissue factor (data not shown).

\section{Local CRP production in pulmonary arterial tissue and cells}

CRP mRNA and protein expression was detected in pulmonary vascular tissue of patients CTEPH (data not shown). CRP expression was highly detectable by immunofluorescence both in SMCs and ECs from pulmonary artery tissue of CTEPH patients (fig. 6).

\section{DISCUSSION}

This article shows that the inflammation marker CRP is able to enhance SMC mitogenic activity, inflammatory cell adhesion to ECs, and secretion of ET-1 and vWF by ECs from CTEPH patients. This suggests that CRP could play a role in the pathophysiology of CTEPH by contributing to the persistence of fibro-thrombotic material obstructing proximal pulmonary arteries. To our knowledge, this is the first study to show a

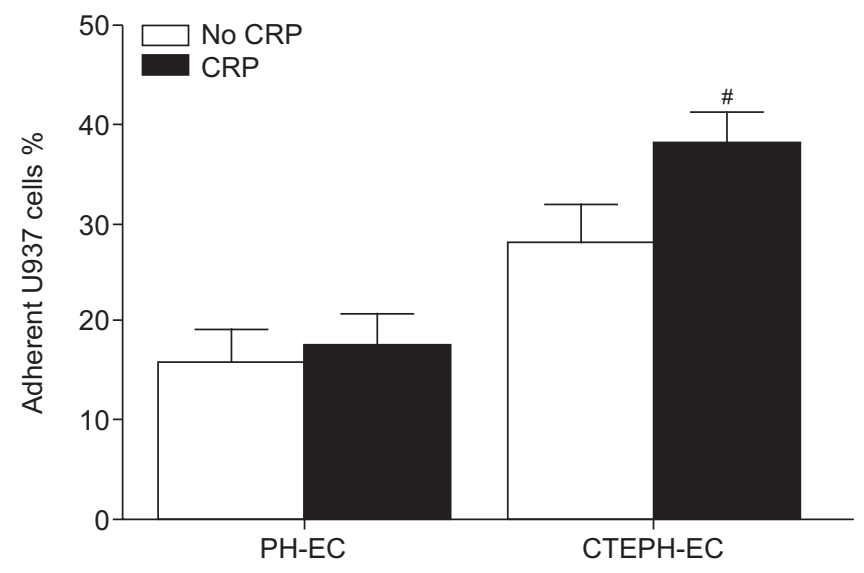

FIGURE 2. Effect of C-reactive protein (CRP) on adhesion capacity of endothelial cells (ECs). Adhesion capacity of proximal ECs isolated from patients with nonthromboembolic pulmonary hypertension $(\mathrm{PH} ; \mathrm{n}=4)$ and chronic thromboembolic pulmonary hypertension (CTEPH) patients $(n=4)$ to monocytic cell line U937 in the absence (control) and in the presence of $10 \mu \mathrm{g} \cdot \mathrm{mL}^{-1} \mathrm{CRP}$. ANOVA $\mathrm{p}=0.002$. \#: $\mathrm{p}<0.005$ versus $\mathrm{PH}-\mathrm{EC}-\mathrm{CRP}$. For each patient, one to three independent experiments were performed in triplicate.

potential contribution of CRP to pulmonary artery cell dysfunction and vascular wall remodelling in CTEPH.

The physiopathology of CTEPH remains incompletely understood. In most cases it is associated with a history of acute venous thromboembolism [19], but why thrombi do not resolve after an acute event in a low percentage of patients is unclear. The current knowledge is based on a triad of enhanced thrombosis [12, 20], disturbed thrombolysis [21-23] and inflammation [3]. These mechanisms were all investigated in the current experiments regarding CRP effects.

By reviewing 200 PEA specimens of fibrotic organised thromboembolic material that adheres to the vessel wall, BERNARD and YI [24] observed cellular proliferation in the wall of recanalising lumens and in the stroma between the lumens. Myxoid changes were prominent in those areas, as well as inflammation, and the authors stated that unknown stimuli for cellular proliferation and inflammatory infiltration might be involved in the pathogenesis of CTEPH. SACKS et al. [25] extensively reviewed the mechanisms that could be responsible for proximal vessel remodelling in CTEPH. However, experimental data regarding the physiopathology of CTEPH are extremely limited.

CRP is an independent biomarker of various inflammatory diseases [9]. We have recently found that elevated circulating CRP levels in CTEPH patients was significantly decreased 12 months after PEA [7]. Besides its known role of bystander and marker of clinical risk in inflammatory diseases, CRP may also be an active player in the pathophysiology of the vascular wall, as has already been demonstrated in atherosclerosis [26, 27].

In the current study, proximal pulmonary vascular cells isolated from CTEPH patients have been compared with proximal pulmonary vascular cells isolated from patients with nonthromboembolic $\mathrm{PH}$ because both pulmonary vasculature are exposed to similar high pressures (table 1). Distal pulmonary vascular cells isolated from $\mathrm{PAH}$ patients have 

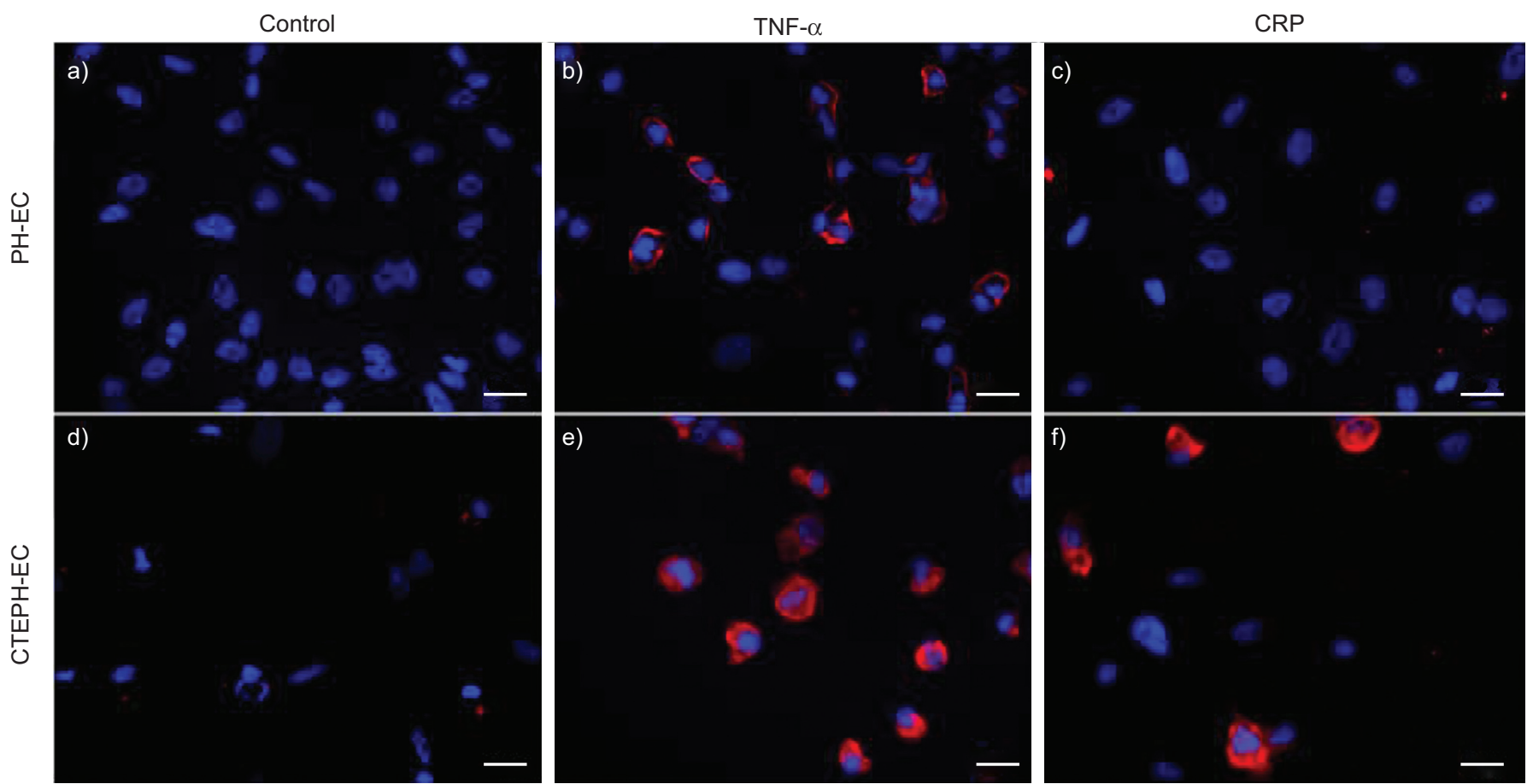

FIGURE 3. Effects of C-reactive protein (CRP) on cell adhesion molecules expression in endothelial cells (ECs). Proximal ECs derived from a-C) patients with nonthromboembolic $\mathrm{PH}$ and $\mathrm{d}-\mathrm{f}$ ) chronic thromboembolic pulmonary hypertension (CTEPH) patients were either not stimulated (a and d), or were stimulated by either $10 \mathrm{ng} \cdot \mathrm{mL}^{-1}$ tumour necrosis factor (TNF)- $\alpha\left(\mathrm{b}\right.$ and e) or $10 \mu \mathrm{g} \cdot \mathrm{mL}^{-1} \mathrm{CRP}$ ( $\mathrm{c}$ and $\mathrm{f}$ ) for $3 \mathrm{~h}$. Cells were further stained with an antibody raised against intercellular adhesion molecule-1 (red). Nuclei were counterstained using 4',6-diamidino-2-phenylindole (blue). Scale bars $=50 \mu \mathrm{m}$

been shown to display enhanced mitogenic activity and ET-1 secretion in vitro compared with control [28]. Nevertheless, proximal pulmonary vascular cells isolated from $\mathrm{PAH}$ patients or patients with $\mathrm{PH}$ due to lung diseases harbour a low proliferation rate, even in the presence of high concentration of FBS (data not shown), and do not secrete ET-1 in vitro. This may suggest that proximal pulmonary vascular cells may harbour different features potentially attributable to the heterogeneity of pulmonary vascular cells along the pulmonary vascular tree [29].

\section{In vitro effects of CRP on pulmonary vascular cells}

The vascular material collected during PEA consists of the neointima and few elastic lamellae from the tunica media of pulmonary arteries and, if present, recent and/or old thrombotic endoluminal material. For the cell culture experiments, fresh and organised thrombotic material was discarded. Neointima formation seems to be an important component of proximal pulmonary artery remodelling in CTEPH, and the CRP-induced CTEPH-SMC proliferation observed in our experiments could, in part, explain this observation (fig. 7). The ET-1 pathway could also be involved in this remodelling (fig. 7). We observed that CRP addition to our CTEPH-ECs induced ET-1 secretion. Others have already shown elevated circulating ET-1 levels in CTEPH patients, together with a correlation with clinical parameters [13]. Addition of CRP also induced ET-1 release in human saphenous vein ECs [15], and adeno-associated virus-mediated CRP gene overexpression caused an increase in ET-1 circulating levels and local aortic expression of ET-1 mRNA in rats [30]. ET-1 also enhanced the pro-atherosclerotic effects of CRP in the systemic circulation [31].
In the present study, we have observed that CRP-induced enhanced adhesion capacity of CTEPH-ECs to the monocytic human cell line U937 could be attributed to CRP-induced ICAM-1, but not to VCAM-1 expression at the EC surface. By contrast, in human umbilical vein ECs, CRP induces VCAM-1, ICAM-1 and E-selectin expression at the cell surface [32]. This could thus explain adhesion and further migration into the vessel wall of inflammatory cells [24] (fig. 7). Taken together, the results of CRP effects on CTEPH-ECs and CTEPH-SMCs suggest a potential role of CRP in endothelium activation and in remodelling of the pulmonary vascular wall in CTEPH. CRP-induced effects on remodelling could either be mediated by ECs through ET-1 release or occur directly, as shown by CRP-induced CTEPH-SMC mitogenic activity.

Our observation that CRP can induce the secretion of vWF by CTEPH-ECs suggests that CRP could contribute to thrombogenesis in CTEPH and consequently to the persistence of pulmonary vessel obstruction (fig. 7). Infusion of CRP in human volunteers results in marked elevations of vWF, prothrombin, D-dimers and plasminogen activator inhibitor type 1 (PAI-1) [33]. CRP also contributes to vascular thrombosis in the systemic circulation by decreasing $\mathrm{NO}$ bioavailability, inhibiting prostaglandin $\mathrm{I}_{2}$ activity, and inducing tissue factor and PAI-1 release [8]. Plasma levels of vWF and of clotting factor VIII have been shown to be elevated in CTEPH patients compared with controls and $\mathrm{PAH}$ patients [12], and differences in the expression of PAI-1 have been observed inside pulmonary thrombi [34].

The specific effects of CRP on proximal pulmonary vascular cells from CTEPH patients could probably be attributed to a 

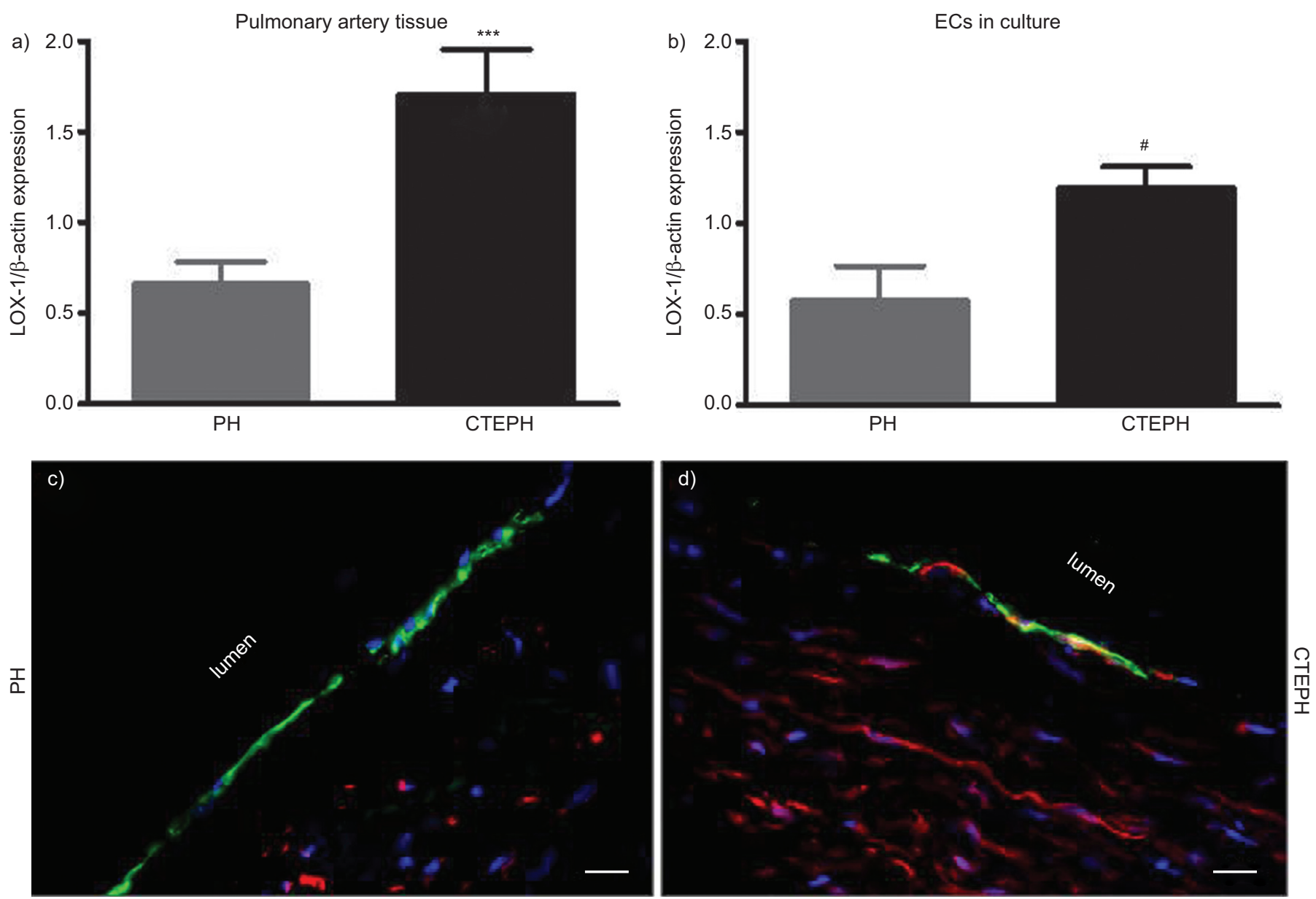

FIGURE 4. Lectin-like oxidised low-density lipoprotein receptor (LOX)-1 expression and localisation in pulmonary vascular cells and tissue. LOX-1 protein expression was measured in a) the proximal pulmonary arteries (PA) and b) primary cultured endothelial cells (ECs) of patients with nonthromboembolic pulmonary hypertension ( $\mathrm{PH}$ ) $(n=10$ for $P A ; n=3$ for ECs) and patients with chronic thromboembolic pulmonary hypertension (CTEPH) $(n=10$ for PA; $n=4$ for ECs). Unpaired t-test. * : $p=0.03 ;$ ***: $p=0.001$. Sections of pulmonary vascular tissue from patients with nonthromboembolic c) PH and d) CTEPH patients were stained with antibodies against LOX-1 (red) and CD31 (green). The two stainings were merged (yellow). Nuclei were counterstained using 4',6-diamidino-2-phenylindole (blue). Scale bars $=50 \mu \mathrm{m}$.

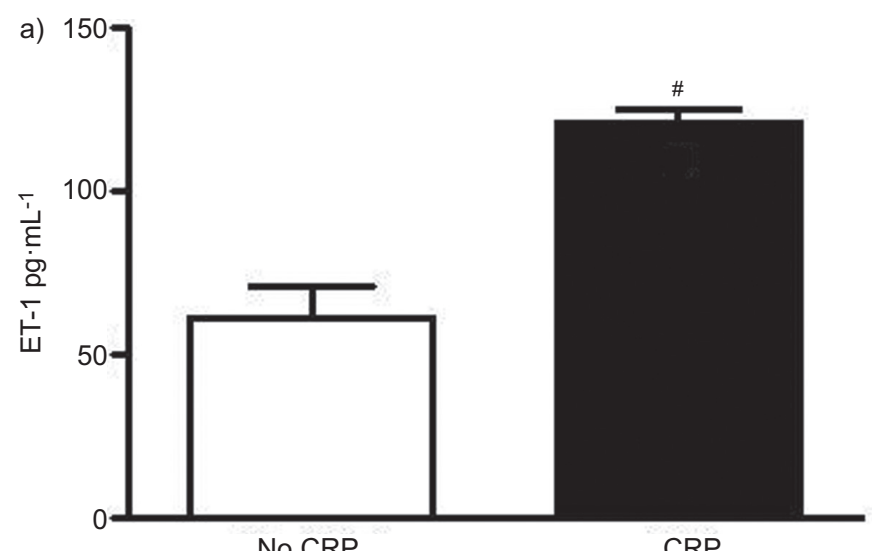

No CRP
CRP

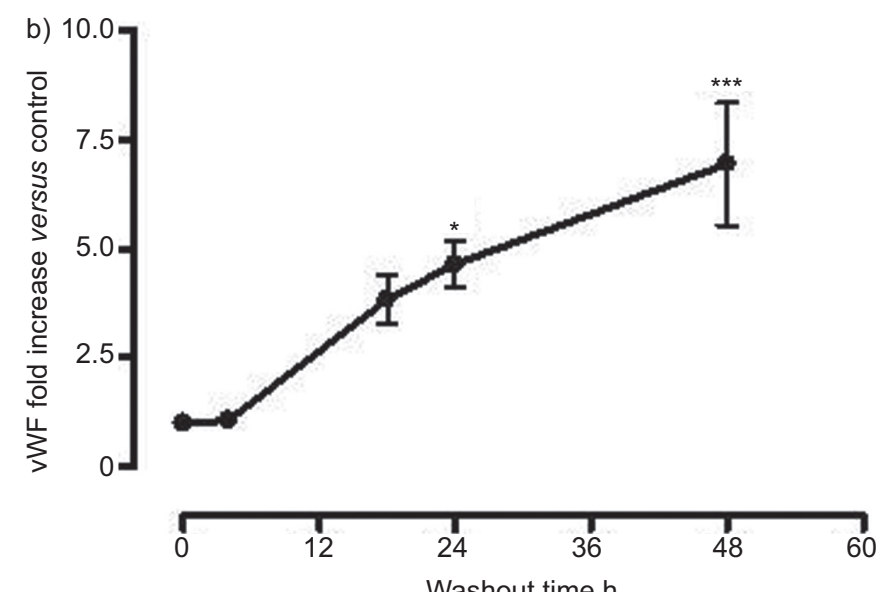

Washout time h

FIGURE 5. Effects of C-reactive protein (CRP) on endothelial function. a) Endothelin (ET)-1 secretion by proximal endothelial cells (ECs) isolated from chronic thromboembolic pulmonary hypertension $(\mathrm{CTEPH})$ patients $(n=4)$ in the absence (control) and in the presence of $\mathrm{CRP}\left(10 \mu \mathrm{g} \cdot \mathrm{mL}^{-1}\right)$. For each patient, one to three independent experiments were performed in triplicate and measurements in duplicate. ${ }^{*}: \mathrm{p}=0.001$ using paired t-test. b) Von Willebrand factor (VWF) secretion by CTEPHECs $(n=6)$ stimulated by CRP. Conditioned medium was collected after 4, 18, 24 and 48 h. ANOVA $p<0.0001$. *: $p<0.05$ versus control; ***: $p<0.001$ versus control. 

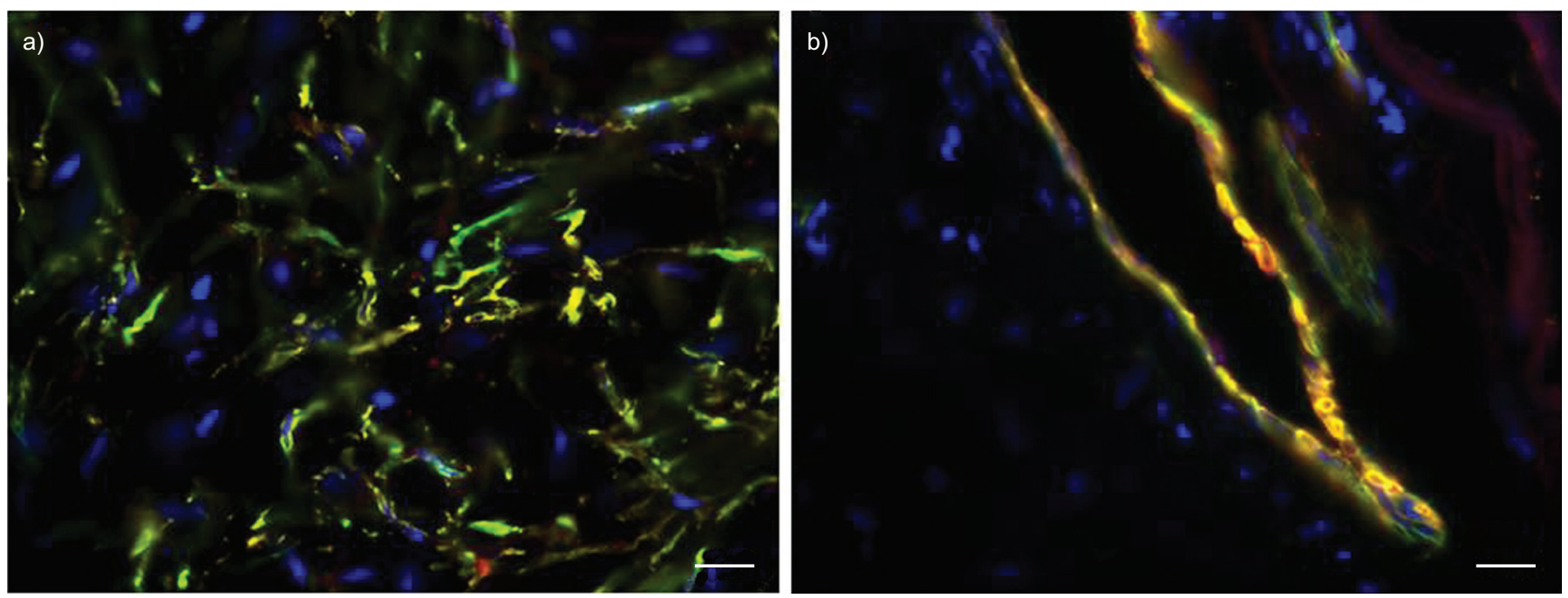

FIGURE 6. Localisation of C-reactive protein (CRP) in pulmonary vascular tissue sections. Sections of pulmonary vascular tissue from chronic thromboembolic pulmonary hypertension (CTEPH) patients were stained with antibodies against CRP (red) and a) $\alpha$-smooth muscle actin (green) or b) CD31 (green). The two stainings were merged (yellow). Nuclei were counterstained using 4',6-diamidino-2-phenylindole (blue). Scale bars $=50 \mu \mathrm{m}$.

differential expression in LOX-1 receptor. In the systemic circulation, CRP mediates its biological effects on endothelial cells mainly via binding to the Fc $\gamma$ receptors CD32 and CD64 [35]. However, we did not find any significant differences in the expression on CD32 and CD64 in pulmonary vascular tissue from CTEPH and nonthromboembolic $\mathrm{PH}$ patients. It has recently been shown that CRP is also a ligand of LOX-1, the primary endothelial receptor for oxLDL [36]. Moreover, oxLDL induced ICAM-1 and VCAM-1 mRNA expression [36] and ET-1 secretion by human umbilical vein ECs [37].

Regarding a potential interference of the anti-inflammatory effects of PAH-targeted therapy with the current results, we observed that circulating CRP levels measured in PAH patients

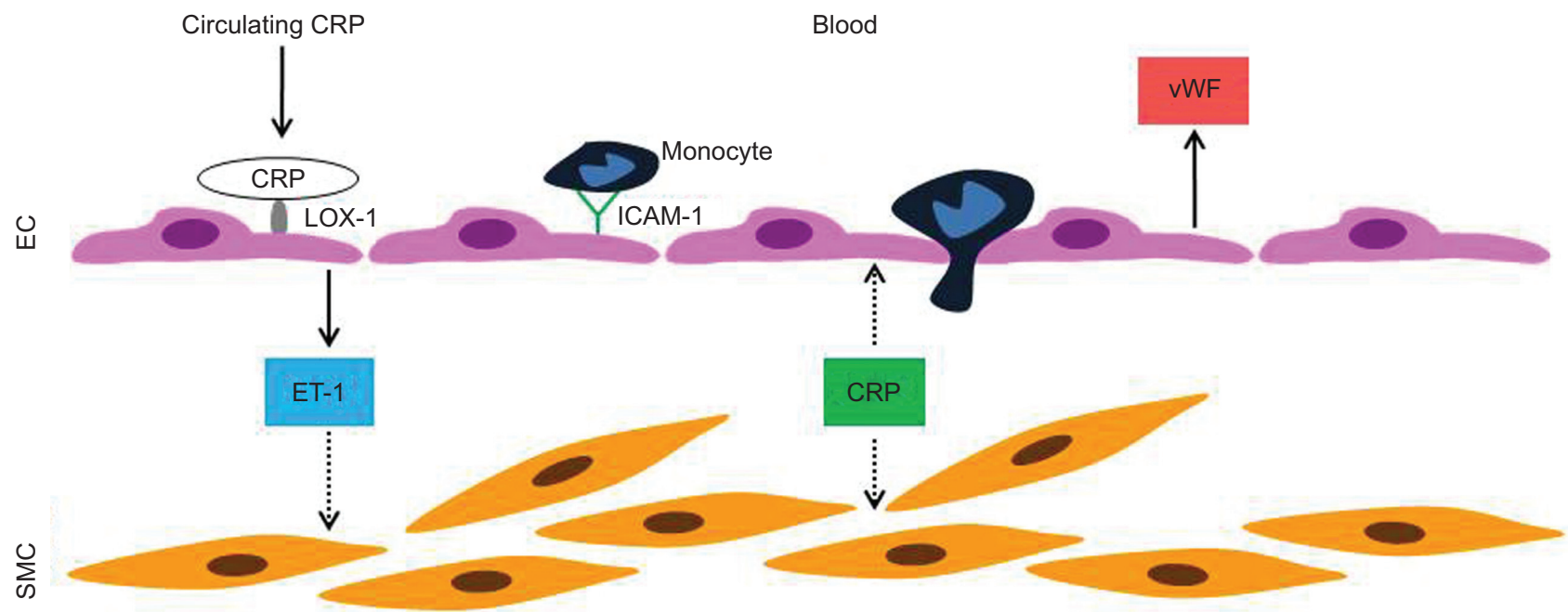

before starting prostanoid therapy and at the time of lung transplantation were unchanged (circulating CRP as geometric mean, used for not normally distributed data, 4.4 (95\% CI 1.117.2) versus $\left.11.4(95 \% \mathrm{CI} 5.4-23.9) \mathrm{mg} \cdot \mathrm{L}^{-1} ; \mathrm{p}=0.11\right)$, as previously shown on a larger number of patients [7]. Moreover, the patient with PAH associated with congenital heart disease who did not receive any prostanoid therapy before transplantation displayed a low LOX-1 expression level similar to the other PAH prostanoid-treated PAH patients. By contrast, two CTEPH patients received epoprostenol for 1-6 months prior to PEA. Circulating CRP levels dropped in these patients. However, each of them showed either an increased adhesion of monocytes to ECs in response to CRP or a high LOX-1 expression level in the proximal pulmonary arteries. Considering the very short

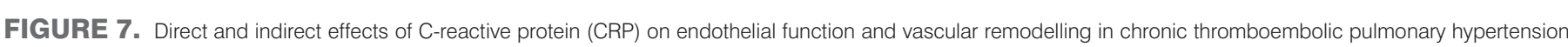

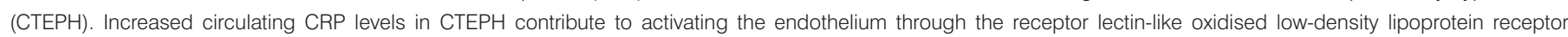

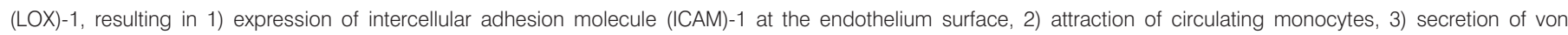

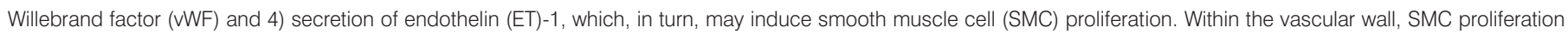
may be induced by CRP produced either by endothelial cells (ECs) or by SMCs themselves. 
half-life of prostanoid molecules, such as epoprostenol (6 min) or treprostinil $(5 \mathrm{~h})$, the chance that an effect of the drug on cells could be maintained in culture for $\sim 1$ month remains very poor. Taken together, all the above observations suggest that prostanoid therapy could hardly interfere with CRP effects on cells in vitro.

\section{Pulmonary vascular production of CRP}

In agreement with previous findings reporting that vascular SMCs are the major source of CRP local production in systemic injured or atherosclerotic arteries [38] and that vascular ECs may also produce CRP [39], this is the first study to report a local production of CRP by ECs and SMCs in CTEPH proximal pulmonary arterial tissue. This locally produced CRP might contribute to endothelial dysfunction, vascular remodelling and in situ thrombosis in CTEPH (fig. 7).

\section{Relevance of the study}

Since the pathophysiology of CTEPH remains poorly understood, an original and unexplored approach was to establish primary cultures of ECs and SMCs derived from CTEPH patients. Our study supports the concept that besides being a surrogate [7], circulating CRP and locally produced CRP could actively contribute to the pathophysiology of CTEPH. Recently, a simple noninvasive diagnostic algorithm, including CRP, has been developed for ruling out CTEPH in patients after acute pulmonary embolism [40].

\section{Conclusions}

Using primary cultures of ECs and SMCs derived from CTEPH patients, we have shown a potential CRP-driven dysfunction of pulmonary vascular cells in CTEPH. In addition to a direct effect of circulating CRP on endothelial cells, CRP produced locally by pulmonary vascular cells could also contribute to vascular remodelling, endothelial dysfunction and in situ thrombosis in CTEPH. Consequently, our results suggest that the inflammation marker, CRP, could play a role in the pathophysiology of CTEPH by contributing to persistence of obstructing material in proximal pulmonary arteries.

\section{SUPPORT STATEMENT}

This work was supported by research grants from Pfizer and from the Belgian Funds for Cardiac Surgery.

\section{STATEMENT OF INTEREST}

Statements of interest for M. Delcroix, and for the study itself can be found at www.erj.ersjournals.com/site/misc/statements.xhtml

\section{ACKNOWLEDGEMENTS}

The authors are grateful to W. Coosemans, P. De Leyn, T. Lerut and P. Nafteux (Thoracic Surgery Department, Universitaire Ziekenhuizen Leuven, Leuven, Belgium) and W. Daenen and F. Rega (Cardiac Surgery Department, Universitaire Ziekenhuizen Leuven, Leuven, Belgium) for their help and collaboration in collecting patient samples. The authors would also like to thank M. Jacquemin and T. Shahani (Center for Molecular and Vascular Biology, Catholic University of Leuven, Leuven, Belgium) for technical help.

\section{REFERENCES}

1 Hoeper MM, Mayer E, Simonneau G, et al. Chronic thromboembolic pulmonary hypertension. Circulation 2006; 113: 2011-2020.
2 Arbustini E, Morbini P, D'Armini AM, et al. Plaque composition in plexogenic and thromboembolic pulmonary hypertension: the critical role of thrombotic material in pultaceous core formation. Heart 2002; 88: 177-182.

3 Bonderman D, Wilkens H, Wakounig S, et al. Risk factors for chronic thromboembolic pulmonary hypertension. Eur Respir J 2009; 33: 325-331.

4 Langer F, Schramm R, Bauer M, et al. Cytokine response to pulmonary thromboendarterectomy. Chest 2004; 126: 135-141.

5 Kimura $\mathrm{H}$, Okada $\mathrm{O}$, Tanabe $\mathrm{N}$, et al. Plasma monocyte chemoattractant protein-1 and pulmonary vascular resistance in chronic thromboembolic pulmonary hypertension. Am J Respir Crit Care Med 2001; 164: 319-324.

6 Bonderman D, Jakowitsch J, Redwan B, et al. Role for Staphylococci in misguided thrombus resolution of chronic thromboembolic pulmonary hypertension. Arterioscler Thromb Vasc Biol 2008; 28: 678-684.

7 Quarck R, Nawrot T, Meyns B, et al. C-reactive protein: a new predictor of adverse outcome in pulmonary arterial hypertension. J Am Coll Cardiol 2009; 53: 1211-1218.

8 Labarrere CA, Zaloga GP. C-reactive protein: from innocent bystander to pivotal mediator of atherosclerosis. Am J Med 2004; 117: 499-507.

9 Devaraj S, Singh U, Jialal I. The evolving role of C-reactive protein in atherothrombosis. Clin Chem 2009; 55: 229-238.

10 Scirica BM, Morrow DA, Verma S, et al. The verdict is still out. Circulation 2006; 113: 2128-2151.

11 Barton M, Yanagisawa M. Endothelin: 20 years from discovery to therapy. Can J Physiol Pharmacol 2008; 86: 485-498.

12 Bonderman D, Turecek PL, Jakowitsch J, et al. High prevalence of elevated clotting factor VIII in chronic thromboembolic pulmonary hypertension. Thromb Haemost 2003; 90: 372-376.

13 Langer F, Bauer M, Tscholl D, et al. Circulating big endothelin-1: an active role in pulmonary thromboendarterectomy? J Thorac Cardiovasc Surg 2005; 130: 1342-1347.

14 Reesink HJ, Meijer RC, Lutter R, et al. Hemodynamic and clinical correlates of endothelin- 1 in chronic thromboembolic pulmonary hypertension. Circ J 2006; 70: 1058-1063.

15 Verma S, Li SH, Badiwala MV, et al. Endothelin antagonism and interleukin-6 inhibition attenuate the proatherogenic effects of Creactive protein. Circulation 2002; 105: 1890-1896.

16 van Mourik JA, Romani de Wit T. Von Willebrand factor propeptide in vascular disorders. Thromb Haemost 2001; 86: 164-171.

17 Ruggeri ZM. The role of von Willebrand factor in thrombus formation. Thromb Res 2007; 120: Suppl. 1, S5-S9.

18 Shahani T, Lavend'homme R, Luttun A, et al. Activation of human endothelial cells from specific vascular beds induces the release of a FVIII storage pool. Blood 2010; 115: 4902-4909.

19 Pepke-Zaba J, Delcroix M, Lang I, et al. Chronic thromboembolic pulmonary hypertension (CTEPH)/clinical perspective. Circulation 2011; 124: 1973-1981.

20 Wolf M, Boyer-Neumann C, Parent F, et al. Thrombotic risk factors in pulmonary hypertension. Eur Respir J 2000; 15: 395-399.

21 Lang IM, Marsh JJ, Olman MA, et al. Parallel analysis of tissue-type plasminogen activator and type 1 plasminogen activator inhibitor in plasma and endothelial cells derived from patients with chronic pulmonary thromboemboli. Circulation 1994; 90: 706-712.

22 Morris TA, Marsh JJ, Chiles PG, et al. High prevalence of dysfibrinogenemia among patients with chronic thromboembolic pulmonary hypertension. Blood 2009; 114: 1929-1936.

23 Suntharalingam J, Goldsmith K, van Marion V, et al. Fibrinogen A $\alpha$ Thr312Ala polymorphism is associated with chronic thromboembolic pulmonary hypertension. Eur Respir J 2008; 31: 736-741.

24 Bernard J, Yi ES. Pulmonary thromboendarterectomy: a clinicopathologic study of 200 consecutive pulmonary thromboendarterectomy cases in one institution. Hum Pathol 2007; 38: 871-877. 
25 Sacks RS, Remillard CV, Agange N, et al. Molecular biology of chronic thromboembolic pulmonary hypertension. Semin Thorac Cardiovasc Surg 2006; 18: 265-276.

26 Sun $\mathrm{H}$, Koike $\mathrm{T}$, Ichikawa $\mathrm{T}$, et al. C-reactive protein in atherosclerotic lesions: its origin and pathophysiological significance. Am J Pathol 2005; 167: 1139-1148.

27 Venugopal SK, Devaraj S, Jialal I. Macrophage conditioned medium induces the expression of C-reactive protein in human aortic endothelial cells: potential for paracrine/autocrine effects. Am J Pathol 2005; 166: 1265-1271.

28 Eddahibi S, Guignabert C, Barlier-Mur AM, et al. Cross talk between endothelial and smooth muscle cells in pulmonary hypertension: critical role for serotonin-induced smooth muscle hyperplasia. Circulation 2006; 113: 1857-1864.

29 Stenmark KR, Frid MG. Smooth muscle cell heterogeneity: role of specific smooth muscle cell subpopulations in pulmonary vascular disease. Chest 1998; 114: 82S-90S.

30 Guan H, Wang P, Hui R, et al. Adeno-associated virus-mediated human C-reactive protein gene delivery causes endothelial dysfunction and hypertension in rats. Clin Chem 2009; 55: 274-284.

31 Ramzy D, Rao V, Tumiati LC, et al. Endothelin-1 accentuates the proatherosclerotic effects associated with C-reactive protein. J Thorac Cardiovasc Surg 2007; 133: 1137-1146.

32 Pasceri V, Willerson JT, Yeh ET. Direct proinflammatory effect of C-reactive protein on human endothelial cells. Circulation 2000; 102: 2165-2168.
33 Bisoendial RJ, Kastelein JJ, Levels JH, et al. Activation of inflammation and coagulation after infusion of C-reactive protein in humans. Circ Res 2005; 96: 714-716.

34 Lang IM, Marsh JJ, Olman MA, et al. Expression of type 1 plasminogen activator inhibitor in chronic pulmonary thromboemboli. Circulation 1994; 89: 2715-2721.

35 Devaraj S, Du Clos TW, Jialal I. Binding and internalization of Creactive protein by Fcgamma receptors on human aortic endothelial cells mediates biological effects. Arterioscler Thromb Vasc Biol 2005; 25: 1359-1363.

36 Shih $\mathrm{HH}$, Zhang S, Cao W, et al. CRP is a novel ligand for the oxidized LDL receptor LOX-1. Am J Physiol Heart Circ Physiol 2009; 296: H1643-H1650.

$37 \mathrm{Ou}$ HC, Song TY, Yeh YC, et al. EGCG protects against oxidized LDL-induced endothelial dysfunction by inhibiting LOX-1mediated signaling. J Appl Physiol 2010; 108: 1745-1756.

38 Inoue $\mathrm{T}$, Kato $\mathrm{T}$, Uchida $\mathrm{T}$, et al. Local release of $\mathrm{C}$-reactive protein from vulnerable plaque or coronary arterial wall injured by stenting. J Am Coll Cardiol 2005; 46: 239-245.

39 De Rosa S, Cirillo P, Pacileo M, et al. Leptin stimulated C-reactive protein production by human coronary artery endothelial cells. J Vasc Res 2009; 46: 609-617.

40 Klok FA, Surie S, Kempf T, et al. A simple non-invasive diagnostic algorithm for ruling out chronic thromboembolic pulmonary hypertension in patients after acute pulmonary embolism. Thromb Res 2011; 128: 21-26. 